\title{
On the application of grey Taguchi method for benchmarking the dimensional accuracy of the PLA fused filament fabrication process
}

\author{
Kyriaki-Evangelia Aslani ${ }^{1} \cdot$ Konstantinos Kitsakis $^{1}$. John D. Kechagias ${ }^{1} \cdot$ Nikolaos M. Vaxevanidis $^{2}$. \\ Dimitrios E. Manolakos ${ }^{3}$
}

Received: 22 February 2020 / Accepted: 24 April 2020 / Published online: 4 May 2020

(c) Springer Nature Switzerland AG 2020

\begin{abstract}
The dimensional accuracy of a simple benchmark specimen fabricated with fused filament fabrication (FFF) route is discussed in the present study. FFF is a low-cost 3D-printing process that builds complicated parts by extruding molten plastic. Experimental method was designed according to Taguchi robust design based on an orthogonal array with nine experiments ( $\mathrm{L}_{9}$ orthogonal array). The printing material was the polylactic acid (PLA). First, Grey-Taguchi method was used for the identification of the optimal printing parameter levels which result in the best dimensional accuracy for the PLA FFF parts. The printing parameters selected included number of shells, printing temperature, infill rate and printing pattern; they were selected in accordance with relevant studies already published. Then, in the second phase, nine specimens were fabricated using the same optimal printing parameter values determined in the first phase. The tolerance of these specimens was characterized according to international tolerance grades (IT grades). Data analysis showed that nozzle temperature is the dominant parameter. Additionally, the parts printed using the optimized process parameter levels possess good dimensional accuracy, which is compatible with the IT grades specification.
\end{abstract}

Keywords Additive manufacturing · FFF · Grey Taguchi optimization method · Dimensional accuracy · IT grade

\section{Introduction}

Unlike conventional subtractive manufacturing processes, Fused Filament Fabrication (FFF) or Fused Deposition Modelling (FDM) is an Additive Manufacturing (AM) method that creates physical objects by melted material deposition layer by layer [1-5]. As a 3D printing procedure, FFF offers several advantages such as producing complex geometries with shorter cycle time and lower cost compared to other traditional manufacturing processes [6-8].

Dimensional accuracy is crucial in any manufacturing process as it is an indicator of how close a dimension of a fabricated piece to the nominal dimension of the designed part is [9]. Tolerance is also very important for every manufactured part, because it is essential for mechanical assemblies such as shafts and holes [10]. Although FFF method has a lot potential advantages, a limiting aspect of its industrial rejection is the obtainable accuracy of the manufactured models [11]. This is the reason why dimensional accuracy of models produced by FFF technology and the factors which affect it, are major issues of examination in the literature.

Mohamed et al. [12] reviewed the literature concerning the determination and the optimization of the FDM process parameters. Notable research work has been done for improving the mechanical properties and part

$\triangle$ John D. Kechagias, jkechag@uth.gr| 1 General Department, University of Thessaly, Gaiopolis, 41500 Larissa, Greece. ${ }^{2}$ Department of Mechanical Engineering Educators, School of Pedagogical and Technological Education (ASPETE), Athens, Greece. ${ }^{3} \mathrm{School}$ of Mechanical Engineering, National Technical University of Athens (NTUA), Athens, Greece. 
quality of FDM ABS parts using statistical design optimization. It is concluded that modelling and optimization of FDM process with other significant FDM materials such as PC, PC-ABS, PPSF, etc., has not been attempted. Moreover, characterization and optimization of FDM process parameters in terms of other properties using statistical experiment design and optimization techniques do not exist in the literature. Turner and Gold [13] reviewed studies related to surface roughness and dimensional accuracy of parts fabricated with the use of FDM process. They found that dimensional accuracy and surface roughness depend on system parameters, such as the ability of control system to manage the flow rate of the material from the print nozzle. Additionally, thermal warping and shrinkage seem to play an important role. Dey and Yodo [14] reviewed a number of FDM process parameters and their impact on dimensional accuracy, surface finish and mechanical properties. They concluded that in terms of dimensional accuracy, layer thickness is one of the most examined and dominant factors. Moreover, high dimensional accuracy is achieved with low layer thickness, number of shells and extrusion temperature values. The impact of many process parameters such as infill pattern and raster width on dimensional accuracy needs further research. Valerga et al. [15] investigated the effect of process parameters and material characteristics of FDM PLA parts on dimensional accuracy, surface quality and mechanical strength. The results showed that the extrusion temperature is the most influential parameter, while the pigmentation of the material and the environmental humidity where it has been stored are also important. Moza et al. [16] studied the dimensional accuracy of FFF parts using two printing materials, PLA and ABS. The experimental results indicated that the dimensional accuracy in $\mathrm{XY}$ plane is mainly affected by the printing material (39.9\%), followed by infill rate $(23.9 \%)$, number of shells (22.5\%) and layer thickness (13.7\%). Additionally, PLA was found to have better dimensional accuracy than ABS. Zero values of deposition angle were used. Sudin et al. [9] investigated the dimensional accuracy of parts produced using the FDM process. They found that the machine's tolerance has a significant effect on the dimensional accuracy of the FDM parts. Moreover, the FDM machine was found to be less accurate in producing circular parts such as cylinder, sphere and hole, as the majority of them are out of the machine's tolerance. Minetola and Galati [10] investigated the dimensional accuracy and the form errors of geometrical features of four different low cost 3D printers. The benchmarking results showed that the most effective modifications of the original printer were those related to the improvement of the structure stiffness and chatter reduction.
Alafaghani et al. [17] investigated the effect of six (6) process parameters (building direction, infill percent, print speed, extrusion temperature, layer height and infill pattern) on dimensional accuracy and mechanical properties of FDM PLA parts. They used an $\mathrm{L}_{18}$ experimental array. They concluded that dimensional accuracy is affected more by building direction, extrusion temperature and layer height than infill percentage, infill pattern, and printing speed. Data analysis was not applied in this research; only some effect graphs. Alafaghani and Qattawi [18] used Taguchi's DOE to investigate the main effects of four processing parameters (infill percentage, infill pattern, layer thickness, and extrusion temperature) of the PLA filament FDM process. They showed that lower values of extrusion temperature, layer thickness and infill percentage along with hexagonal infill pattern are required for better dimensional accuracy. On the other hand, in order to increase the strength of FDM parts, higher extrusion temperature, optimized layer thickness, triangular infill pattern and higher infill percentage are needed. Mahmood et al. [19] investigated extensively the geometrical characteristics of ABS filament FDM printed parts. A prototype with simple geometric features was designed, which allowed measurements for both dimensional accuracy and geometric properties. Deposition angle was set at zero for all the experiments. Statistical analysis was utilized for the determination of the process parameter levels which affect most the geometrical properties of the designed prototype. They concluded that the number of shells $(E)$, was the most important factor affecting the dimensional accuracy of the printed part. This was followed by the inset distance multiplier ( $G$ ), the space between adjacent shells, chamber temperature $(A)$, infill shell spacing multiplier $(F)$, the amount of overlap between the innermost shell and the adjacent infill extrusion and the infill density (K). These five factors were found to be the most sensitive for the identification of the part's printing accuracy. Layer thickness proved that was not so important in this research. Vishwas et al. [20] optimized the process parameter levels for FDM printed parts in terms of dimensional accuracy and tensile strength. They utilized $A B S$ and Nylon as printing materials and Taguchi's $L_{9}$ orthogonal array. The process parameters were orientation angle, layer thickness and shell thickness. They found that in case of $A B S$ $0.2 \mathrm{~mm}$ layer thickness, 300 orientation angle and 0.8 $\mathrm{mm}$ shell thickness gave the best dimensional accuracy, whereas in case of Nylon, the corresponding levels were $0.3 \mathrm{~mm}$ layer thickness, 150 orientation angle and 0.4 $\mathrm{mm}$ shell thickness.

The following conclusions can been drawn from the above literature review: 
1 Stiffness and chatter reduction of 3D printers should be improved in order to achieve better process performance [10].

2 Geometrical features and deposition angle (orientation of STL model) are very important for the quality performance of 3D printed parts $[9,18]$. Optimization of these parameters is needed before the 3D printing process starts.

3 Layer thickness has small effect on XY plane dimensional accuracy, when zero values of deposition angle are used $[16,19]$. When deposition angle is changed, effect of layer thickness on XY plane dimensional accuracy is observed $[10,17,18]$; in these cases smaller values of layer thickness give the best performance.

4 Number of shells, infill rate, and printing (infill) pattern affect significantly the process quality performance $[9-12,14,16-20]$.

Based on the above conclusions, an experiment for optimizing the FFF process' dimensional accuracy was designed using four (4) process parameters (number of shells, printing nozzle temperature, infill rate and printing pattern. Deposition angle and layer thickness were held constant (zero angle and $0.2 \mathrm{~mm}$, correspondingly) throughout the whole process. As it is mentioned above, when zero values of deposition angle are used, layer thickness has small effect on XY plane dimensional accuracy $[16,19]$. PLA material was used as the printing material as it was found to give better dimensional accuracy performance [16].

For optimization purposes, an $\mathrm{L}_{9}$ orthogonal array (OA) was designed and nine (9) parts were built as the first run. Then, Grey Taguchi approach was used along with ANOM and ANOVA techniques to identify the process parameters which affect the dimensional accuracy and to establish an optimal selection of them. After the selection of the best printing parameter levels, nine (9) new parts (replicas) were printed as a second run, using only these particular printing parameter values. Finally, international tolerance (IT) grade was used for specifying the tolerances of these nine replicas. To the best of authors' knowledge, the tolerance characterization of FFF PLA parts printed with the use of the optimized printing parameters levels has not been addressed before.

\section{Experimental procedure}

\subsection{Preparation of 3D printed PLA specimens}

In this investigation, a 3D model was created, consisting of a square base with three orthogonal parallelepiped features. The nominal dimensions of these parallelepiped

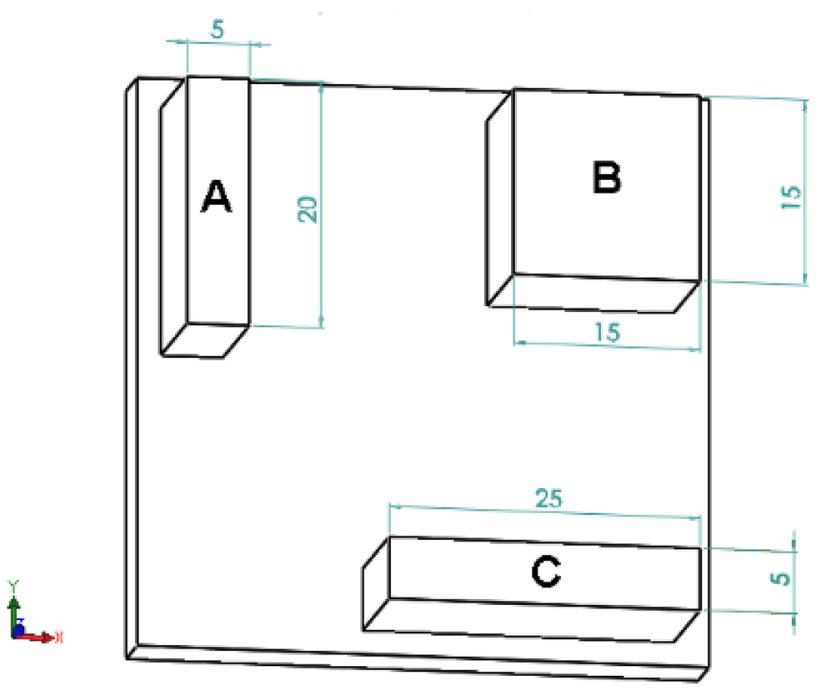

Fig. 1 Printed model and feature dimensions

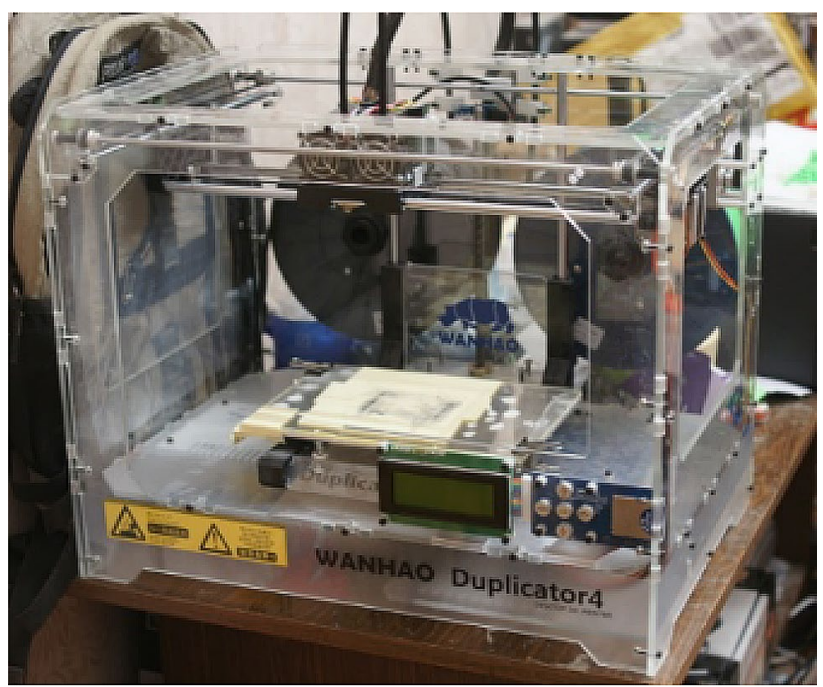

Fig. 2 Wanhao duplicator 4X 3D printer [16]

features for $X$ and $Y$ directions are shown in Fig. 1. The base's height is $2 \mathrm{~mm}$, while feature's height is $5 \mathrm{~mm}$. This 3D model was designed by Solidworks software and it was extracted in STL format. The 3D printer which was used was Wanhao Duplicator 4X (Fig. 2) [16], while the printing material was polylactic acid (PLA). PLA is a thermoplastic polyester and it is produced by renewable resources such as corn starch, tapioca roots or sugarcane [21]. MakerBot Print desktop application was also used for preparing, managing and monitoring all $3 \mathrm{D}$ prints. At the first attempt of this project, nine specimens were printed (Fig. 3). Different combination of process parameters' values was used each time, according to $L_{9}$ Taguchi design. 


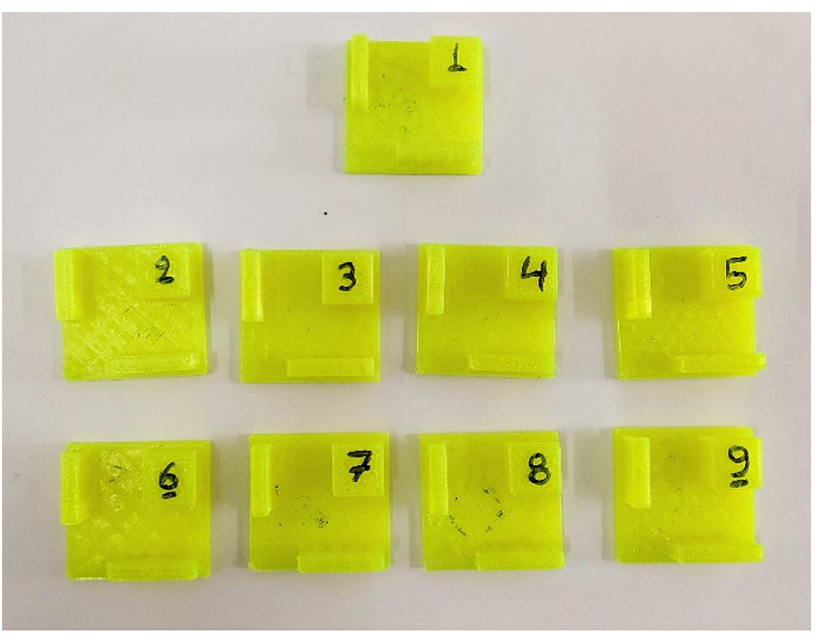

Fig. 3 Printed parts for process optimization (first run)

Table 1 Different process parameters and their levels

\begin{tabular}{llll}
\hline Process parameters & \multicolumn{2}{l}{ Levels } \\
\cline { 2 - 4 } & 1 & 2 & 3 \\
\hline Number of shells $(-)$ & 2 & 3 & - \\
Printing temperature $\left({ }^{\circ} \mathrm{C}\right)$ & 210 & 220 & 230 \\
Infill rate $(\%)$ & 10 & 15 & 20 \\
Printing pattern $(-)$ & $\mathrm{D}$ & $\mathrm{E}$ & $\mathrm{R}$ \\
\hline
\end{tabular}

These nine specimens were used for the parameters' optimization. At the second run, after the selection of the best process parameter levels according to the Grey Taguchi study that has been executed (see Sect. 3), nine new parts were printed using the same 3D model and printer.

\subsection{Preparation of 3D printed PLA specimens}

The dimensional accuracy of parts created using FFF technology is affected strongly by the process parameters' values that are selected during the printing process (see Sect. 1). The process parameters whose impact on the dimensional accuracy is studied here are: number of shells, printing temperature, infill rate and printing pattern. For experimentation, two or three levels have been selected for each printing parameter. Table 1 outlines the FFF printing parameters and their levels that are used in this study. The process parameters are briefly defined as follows:

- Number of shells: It is a key parameter which defines the outline shape and inner support structure of an object. At least one shell is needed for printing an object and additional shells add strength and weight but increase the printing time [22].
- Printing temperature: It is the temperature that the material is heated to during the printing process. The recommended printing temperature for PLA is 195$230^{\circ} \mathrm{C}[23]$.

- Infill rate: It is the ratio of printed material to air volume and its value vary from 0 to $100 \%$. It controls the final mass density of the 3D printed part. Once selected, the infill value is constant throughout the fabricated object and cannot be altered mid-print [24].

- Printing pattern: It is the geometric pattern that it is used in the printing process [25]. The capitals letters assigned as: D for diamond fill, E for hexagonal and R for linear.

As it is analyzed in Sect. 1, a number of process parameters such as deposition angle, layer thickness and printing speeds were held constant throughout the printing process. These parameters and their values are:

\section{- Deposition angle: $0^{\circ}$}

The value of this parameter should be chosen before the start of the printing process, according to geometrical features and shape of the model $[9,18]$.

- Layer thickness: $0.2 \mathrm{~mm}$

When deposition angle is zero, layer thickness has small effect on XY plane dimensional accuracy $[16,19]$.

- Printing material: PLA

PLA material was found to give better dimensional accuracy [16].

- Printing speeds

- Travel speed: $150 \mathrm{~mm} / \mathrm{s}$

This speed occurs when printer is not extruding material.

- Infill printing speed: $90 \mathrm{~mm} / \mathrm{s}$

- Shell printing speed: $40 \mathrm{~mm} / \mathrm{s}$

In general, speed and material's deposition volume are related. These parameters are very important and are associated with stiffness and printer's design [10]. They are kept constant, because when they are increased, the quality and the dimensional accuracy of the printed models become worse. Analytical and arithmetical models should be developed in order to optimize these parameters.

- Printing table temperature: $70^{\circ} \mathrm{C}$

- Environment temperature: $25^{\circ} \mathrm{C}$

\subsection{Design of experiments (first run)}

In this research, Taguchi's orthogonal array has been used for the design of experiments. Taguchi's design is generally adopted by a number of researchers in order to make 
experiments with smaller number of trials [26-28]. This method provides an efficient and systematic approach to optimize a number experiments and the utility to study the interaction effects among parameters [29]. In Taguchi design, selection of the proper orthogonal array is a very important issue in order to obtain valid conclusions. Since there is one factor with two levels and three factors with three levels, the appropriate orthogonal array for this case is $L_{g}$. Many researchers have utilized the $L_{9}$ orthogonal array for the optimization of various manufacturing processes. Singh et al. [30] used an $\mathrm{L}_{9}$ array to optimize the dimensional accuracy and surface roughness of an Investment Casting (IC) printed implant. Sundaramoorthy et al. [31] investigated the optimum tool wear of CNC milling magnesium silicide alloys with the use of Taguchi's $L_{9}$ orthogonal array. Satyanarayana et al. [32] studied the optimized laser welding process parameters for P92 steel using an $\mathrm{L}_{9}$ array and modified Taguchi design of experiments. The $L_{9}$ orthogonal array with all process parameters and their levels that has been used in this study is shown in Table 2.

\subsection{Dimensional measurement techniques (first and second run)}

For all nine components, both in the case of using $L_{9}$ DOE and the best parameter levels in printing, dimensions of the three features were measured in $X$ and $Y$ direction (see Fig. 1). Three measurements were conducted for every direction and their average value was calculated. Next, dimensional deviation was computed, which shows the difference between the nominal and the average measured values and represents dimensional accuracy of the parts. The goal here is to find the process parameter levels that minimize dimensional deviation for both directions, then using these levels for printing new parts and study their dimensional

Table $2 L_{9}$ experimental design for selected process parameters and their levels

\begin{tabular}{lllll}
\hline Exp. no. & $\begin{array}{l}\text { Number of } \\
\text { cells }(-)\end{array}$ & $\begin{array}{l}\text { Temperature } \\
\left({ }^{\circ} \mathrm{C}\right)\end{array}$ & Infill (\%) & Pattern $(-)$ \\
\hline 1 & 2 & 210 & 10 & $\mathrm{E}$ \\
2 & 2 & 220 & 15 & $\mathrm{D}$ \\
3 & 2 & 230 & 20 & $\mathrm{R}$ \\
4 & 3 & 210 & 15 & $\mathrm{R}$ \\
5 & 3 & 220 & 20 & $\mathrm{E}$ \\
6 & 3 & 230 & 10 & $\mathrm{D}$ \\
7 & 2 & 210 & 20 & $\mathrm{D}$ \\
8 & 2 & 220 & 10 & $\mathrm{R}$ \\
9 & 2 & 230 & 15 & $\mathrm{E}$ \\
\hline
\end{tabular}

deviation and tolerance. A micrometre with $0-25 \mathrm{~mm}$ range and $0.01 \mathrm{~mm}$ accuracy was used for the dimensional measurements. Average dimension values, nominal dimension values and deviation of each feature for the nine DOE parts are shown in Table 3 (first run).

\section{Statistical analysis of DOE parts (first run)}

\subsection{Grey Taguchi approach}

The Taguchi method optimizes single response performance, but for multiple responses optimization gets complex [33]. In this case, grey relational analysis optimization methodology is recommended. The Grey-Taguchi approach is an advanced form of the Taguchi method. It is used for the optimization of more than one responses rather than optimizing a single response as in case of the classic Taguchi approach [34]. In this investigation, Grey-Taguchi method is employed to find the best level arrangement of both $X$ and $Y$ dimensional deviation of all three features.

In the grey Taguchi method, all dimensional deviation results (six in total, see Table 3 ) are first normalized to a range of $0-1$. Then, the grey relational coefficient is calculated in order to relate the desired and actual normalized data. Next, the grey relational grade is derived, by averaging the previous calculated grey relational coefficient values. The optimization of the grey relational grade is equivalent with the optimization of the multiple process responses. The optimum printing parameter levels are computed by maximizing the grey relational grade [35, 36]. The normalized deviation values which correspond to the smaller-the-better are expressed as:

$x_{i j}=\frac{\max y_{i j}-y_{i j}}{\max y_{i j}-\min y_{i j}}$

where $x_{i j}$ is the normalized deviation value, miny $y_{i j}$ is the lowest value of ith experiment in the jth response and $\operatorname{maxy}_{i j}$ is the highest value of ith experiment in the jth responce. Table 4 shows the normalized deviation results of all the experiments.

The grey relational coefficient $\gamma$ can be calculated as:

$\gamma_{i j}=\frac{\Delta_{\min }+\zeta \Delta_{\max }}{\Delta_{i j}+\zeta \Delta_{\max }}$

where $\Delta_{i j}=\left|x_{0 j}-x_{i j}\right|, \Delta_{\min }=\min \Delta_{i j}$ for all $\mathrm{i}$ and $\mathrm{j}$, $\Delta_{\max }=\max \Delta_{i j}$ for all $i$ and $j$ while $\zeta$ is called distinguishing coefficient $(0 \sim 1)$. The value of the distinguishing coefficient is considered as 0.5 in this research. The grey relational coefficient values are tabulated in Table 5 . 
Table 3 Dimensional accuracy measurement results for nine printed parts (first run)

\begin{tabular}{|c|c|c|c|c|c|c|}
\hline \multirow[t]{3}{*}{ Feature } & \multicolumn{2}{|c|}{ Nominal dimension (mm) } & \multicolumn{4}{|c|}{ Measured dimension (mm) } \\
\hline & \multirow[t]{2}{*}{$\mathrm{X}$ direction } & \multirow[t]{2}{*}{ Y direction } & \multicolumn{2}{|c|}{$\mathrm{X}$ direction } & \multicolumn{2}{|c|}{ Y direction } \\
\hline & & & Average & Deviation & Average & Deviation \\
\hline \multirow[t]{9}{*}{ A } & \multirow[t]{9}{*}{5} & \multirow[t]{9}{*}{20} & 5.063 & 0.063 & 19.940 & 0.060 \\
\hline & & & 5.063 & 0.063 & 19.850 & 0.150 \\
\hline & & & 5.040 & 0.040 & 19.890 & 0.110 \\
\hline & & & 5.113 & 0.113 & 19.990 & 0.010 \\
\hline & & & 4.963 & 0.037 & 19.930 & 0.070 \\
\hline & & & 5.090 & 0.090 & 20.030 & 0.030 \\
\hline & & & 5.070 & 0.070 & 19.920 & 0.080 \\
\hline & & & 5.257 & 0.257 & 19.890 & 0.110 \\
\hline & & & 5.007 & 0.007 & 19.920 & 0.080 \\
\hline \multirow[t]{9}{*}{ B } & \multirow[t]{9}{*}{15} & \multirow[t]{9}{*}{15} & 14.855 & 0.145 & 14.905 & 0.095 \\
\hline & & & 14.825 & 0.175 & 14.915 & 0.085 \\
\hline & & & 14.875 & 0.125 & 15.055 & 0.055 \\
\hline & & & 14.845 & 0.155 & 15.045 & 0.045 \\
\hline & & & 14.785 & 0.215 & 14.895 & 0.105 \\
\hline & & & 14.950 & 0.050 & 15.005 & 0.005 \\
\hline & & & 14.750 & 0.250 & 14.865 & 0.135 \\
\hline & & & 14.825 & 0.175 & 14.970 & 0.030 \\
\hline & & & 14.750 & 0.250 & 14.975 & 0.025 \\
\hline \multirow[t]{9}{*}{$C$} & \multirow[t]{9}{*}{25} & \multirow[t]{9}{*}{5} & 24.670 & 0.330 & 5.107 & 0.107 \\
\hline & & & 24.610 & 0.390 & 5.087 & 0.087 \\
\hline & & & 24.800 & 0.200 & 5.100 & 0.100 \\
\hline & & & 24.640 & 0.360 & 5.127 & 0.127 \\
\hline & & & 24.750 & 0.250 & 5.040 & 0.040 \\
\hline & & & 24.670 & 0.330 & 5.067 & 0.067 \\
\hline & & & 24.650 & 0.350 & 5.113 & 0.113 \\
\hline & & & 24.670 & 0.330 & 5.043 & 0.043 \\
\hline & & & 24.640 & 0.360 & 5.020 & 0.020 \\
\hline
\end{tabular}

Table 4 Normalized deviation values $x_{i j}$

\begin{tabular}{|c|c|c|c|c|c|}
\hline \multicolumn{2}{|l|}{ Feature $\mathrm{A}$} & \multicolumn{2}{|l|}{ Feature B } & \multicolumn{2}{|l|}{ Feature $\mathrm{C}$} \\
\hline $\mathrm{X}$ direction & Y direction & $\mathrm{X}$ direction & Y direction & $\mathrm{X}$ direction & Y direction \\
\hline 0.7733 & 0.6429 & 0.5250 & 0.3077 & 0.3150 & 0.1875 \\
\hline 0.7733 & 0.0000 & 0.3750 & 0.3846 & 0.0000 & 0.3750 \\
\hline 0.8667 & 0.2857 & 0.6250 & 0.6154 & 1.0000 & 0.2500 \\
\hline 0.5733 & 1.0000 & 0.4750 & 0.6923 & 0.1579 & 0.0000 \\
\hline 0.8800 & 0.5714 & 0.1750 & 0.2308 & 0.7368 & 0.8125 \\
\hline 0.6667 & 0.8571 & 1.0000 & 1.0000 & 0.3158 & 0.5625 \\
\hline 0.7467 & 0.5000 & 0.0000 & 0.0000 & 0.2105 & 0.1250 \\
\hline 0.0000 & 0.2857 & 0.3750 & 0.8077 & 0.3158 & 0.7813 \\
\hline 1.0000 & 0.5000 & 0.0000 & 0.8462 & 0.1579 & 1.0000 \\
\hline
\end{tabular}

The grey relational grade can be derived as:

$\alpha_{i}=\sum_{i=1}^{n} \gamma_{i j}$
Table 6 shows the grey relational grade calculation results of each $L_{9}$ orthogonal array's experiment and their optimization order. 
Table 5 Grey relational coefficient $\gamma$ results

\begin{tabular}{|c|c|c|c|c|c|}
\hline \multicolumn{2}{|l|}{ Feature $\mathrm{A}$} & \multicolumn{2}{|l|}{ Feature B } & \multicolumn{2}{|l|}{ Feature $\mathrm{C}$} \\
\hline $\mathrm{X}$ direction & Y direction & $\mathrm{X}$ direction & Y direction & $\mathrm{X}$ direction & Y direction \\
\hline 0.6881 & 0.5833 & 0.5128 & 0.4194 & 0.4222 & 0.3809 \\
\hline 0.6881 & 0.3333 & 0.4444 & 0.4483 & 0.3333 & 0.4444 \\
\hline 0.7895 & 0.4118 & 0.5714 & 0.5652 & 1.0000 & 0.4000 \\
\hline 0.5396 & 1.0000 & 0.4878 & 0.6190 & 0.3725 & 0.3333 \\
\hline 0.8065 & 0.5385 & 0.3774 & 0.3939 & 0.6552 & 0.7272 \\
\hline 0.6000 & 0.7778 & 1.0000 & 1.0000 & 0.4222 & 0.5333 \\
\hline 0.6637 & 0.5000 & 0.3333 & 0.3333 & 0.3878 & 0.3636 \\
\hline 0.3333 & 0.4118 & 0.4444 & 0.7222 & 0.4222 & 0.6957 \\
\hline 1.0000 & 0.5000 & 0.3333 & 0.7647 & 0.3725 & 1.0000 \\
\hline
\end{tabular}

Table 6 Grey relational grade calculation results

\begin{tabular}{lllllll}
\hline Exp. no. & $\begin{array}{l}\text { Number of } \\
\text { cells }(-)\end{array}$ & Temperature $\left({ }^{\circ} \mathrm{C}\right)$ & Infill $(\%)$ & Pattern $(-)$ & $\begin{array}{l}\text { Grey relational } \\
\text { grade }\end{array}$ & Order \\
\hline 1 & 2 & 210 & 10 & $\mathrm{E}$ & 0.5011 & 7 \\
2 & 2 & 220 & 15 & $\mathrm{D}$ & 0.4487 & 8 \\
3 & 2 & 230 & 20 & $\mathrm{R}$ & 0.6230 & 3 \\
4 & 3 & 210 & 15 & $\mathrm{R}$ & 0.5587 & 5 \\
5 & 3 & 220 & 20 & $\mathrm{E}$ & 0.5831 & 4 \\
6 & 3 & 230 & 10 & $\mathrm{D}$ & 0.7222 & 1 \\
7 & 2 & 210 & $\mathrm{D}$ & 0.4303 & 9 \\
8 & 2 & 220 & 10 & $\mathrm{R}$ & 0.5049 & 6 \\
9 & 2 & 230 & 15 & $\mathrm{E}$ & 0.6618 & 2 \\
\hline
\end{tabular}

Table 7 Response table for the mean (ANOM) values of the grey relational grade

\begin{tabular}{lllll}
\hline Level & Number of cells & Temperature $\left({ }^{\circ} \mathrm{C}\right)$ & Infill (\%) & Pattern \\
\hline 1 & 0.5283 & 0.4967 & 0.5761 & 0.5337 \\
2 & 0.6213 & 0.5122 & 0.5564 & 0.5820 \\
3 & - & 0.6690 & 0.5455 & 0.5622 \\
Delta & 0.0931 & 0.1723 & 0.0306 & 0.0483 \\
Rank & 2 & 1 & 4 & 3 \\
\hline
\end{tabular}

\subsection{ANOM and ANOVA for grey relational grade results}

In this study, the statistical analysis and the plots were conducted with the use of Minitab 17 Statistical Software. Table 7 outlines the mean grey relational grade values calculated with the Analysis of Means (ANOM). It has been revealed that temperature is the most influential printing parameter followed by number of cells, pattern and infill. The optimal parameter levels are those that have the highest grey relational grade value as it is shown in the plot of means (Fig. 4). These levels are: (a) Number of cells: 3 , (b) Temperature: $230^{\circ} \mathrm{C}$, (c) Infill: $10 \%$, (d) Pattern: E.

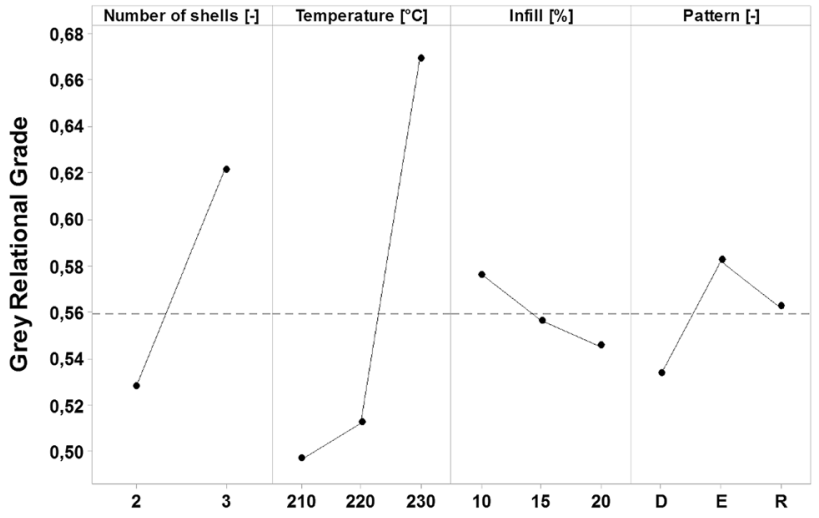

Fig. 4 Plot of means for grey relational grade

Table 8 Response table for ANOVA of grey relational grade

\begin{tabular}{llllll}
\hline Source & $d f$ & Adj. SS & Adj. MS & F value & $P$ value \\
\hline Number of cells & 1 & 0.017319 & 0.017319 & 176.81 & 0.048 \\
Temperature $\left({ }^{\circ} \mathrm{C}\right)$ & 2 & 0.054492 & 0.027246 & 278.16 & 0.042 \\
Infill (\%) & 2 & 0.001446 & 0.000723 & 7.38 & 0.252 \\
Pattern & 2 & 0.003534 & 0.001767 & 18.04 & 0.164 \\
Error & 1 & 0.000098 & 0.000098 & - & - \\
Total & 8 & 0.076890 & - & - & - \\
\hline
\end{tabular}


The purpose of the Analysis of Variance (ANOVA) is to investigate which process parameters affect significantly the dimensional accuracy. Two values, the $\mathrm{F}$ and $P$ value are computed for this reason. High $F$ values imply that a parameter is important; so do small $P$ values $(P<0.05)$. The ANOVA results for grey relational grade are tabulated in Table 8. It is appeared that the temperature is the most influential parameter $(\mathrm{F}=278.16, P=0.042<0.05)$, followed by number of cells $(F=176.81, P=0.048<0.05)$. The other two process parameters are not so important. It should be noted that the ANOM gave the same results as ANOVA in terms of process parameter significance.

\section{Tolerance grade study of optimized parts (second run)}

In this research, a multi-response optimization was executed regarding dimensional deviations for two dimensions, using Grey Taguchi approach and statistical analysis. The whole study showed that the optimal printing parameters which result in best dimensional accuracy are: (a) Number of cells: 3 , (b) Temperature: $230^{\circ} \mathrm{C}$, (c) Infill: $10 \%$, (d) Pattern: $E$ (see Sect. 3.2). Nine parts were printed using only these particular process parameter levels with the same design and $3 \mathrm{D}$ printer as the ones used in $\mathrm{DOE}$ parts (see Sect. 2.1). Features A, B and C of the new parts were measured in $X$ and $Y$ direction. Three measurements were taken for every direction again. Table 9 shows the highest and lowest measured dimensional values and their deviation for the three features in $\mathrm{X}$ and $\mathrm{Y}$ direction.
Table 9 Highest, lowest and deviation values of the measured dimensions of the optimized parts

\begin{tabular}{|c|c|c|c|c|c|c|c|c|}
\hline \multirow[t]{3}{*}{ Feature } & \multicolumn{2}{|c|}{ Nominal dimension (mm) } & \multicolumn{6}{|c|}{ Measured dimension (mm) } \\
\hline & \multirow[t]{2}{*}{$\mathrm{X}$ direction } & \multirow[t]{2}{*}{ Y direction } & \multicolumn{3}{|c|}{$\mathrm{X}$ direction } & \multicolumn{3}{|c|}{ Y direction } \\
\hline & & & Min & Max & Deviation & Min & Max & Deviation \\
\hline \multirow[t]{9}{*}{$A$} & \multirow[t]{9}{*}{5} & \multirow[t]{9}{*}{20} & 5.02 & 5.03 & 0.01 & 19.96 & 19.99 & 0.03 \\
\hline & & & 5.01 & 5.02 & 0.01 & 19.96 & 19.98 & 0.02 \\
\hline & & & 5.00 & 5.03 & 0.03 & 19.98 & 19.99 & 0.01 \\
\hline & & & 5.00 & 5.01 & 0.01 & 19.98 & 19.99 & 0.01 \\
\hline & & & 5.03 & 5.05 & 0.02 & 20.00 & 20.01 & 0.01 \\
\hline & & & 5.01 & 5.01 & 0.00 & 19.99 & 20.01 & 0.02 \\
\hline & & & 5.02 & 5.05 & 0.03 & 20.00 & 20.02 & 0.02 \\
\hline & & & 5.01 & 5.03 & 0.02 & 19.98 & 19.99 & 0.01 \\
\hline & & & 5.01 & 5.02 & 0.01 & 20.00 & 20.01 & 0.01 \\
\hline \multirow[t]{9}{*}{ B } & \multirow[t]{9}{*}{15} & \multirow[t]{9}{*}{15} & 15.01 & 15.02 & 0.01 & 15.02 & 15.04 & 0.02 \\
\hline & & & 15.01 & 15.02 & 0.01 & 15.04 & 15.04 & 0.00 \\
\hline & & & 15.03 & 15.05 & 0.02 & 15.02 & 15.03 & 0.01 \\
\hline & & & 14.98 & 14.99 & 0.01 & 14.99 & 15.01 & 0.02 \\
\hline & & & 14.99 & 14.99 & 0.00 & 15.00 & 15.01 & 0.01 \\
\hline & & & 15.03 & 15.06 & 0.03 & 14.99 & 15.00 & 0.01 \\
\hline & & & 15.01 & 15.02 & 0.01 & 15.02 & 15.03 & 0.01 \\
\hline & & & 15.02 & 15.03 & 0.01 & 15.01 & 15.03 & 0.02 \\
\hline & & & 14.99 & 15.02 & 0.03 & 14.98 & 14.99 & 0.01 \\
\hline \multirow[t]{9}{*}{ C } & \multirow[t]{9}{*}{25} & \multirow[t]{9}{*}{5} & 24.82 & 24.85 & 0.03 & 5.06 & 5.08 & 0.02 \\
\hline & & & 24.83 & 24.85 & 0.02 & 5.06 & 5.09 & 0.03 \\
\hline & & & 24.85 & 24.86 & 0.01 & 5.05 & 5.06 & 0.01 \\
\hline & & & 24.83 & 24.84 & 0.01 & 5.01 & 5.04 & 0.03 \\
\hline & & & 24.85 & 24.85 & 0.00 & 5.06 & 5.07 & 0.01 \\
\hline & & & 24.85 & 24.86 & 0.01 & 5.06 & 5.06 & 0.00 \\
\hline & & & 24.85 & 24.87 & 0.02 & 5.07 & 5.08 & 0.01 \\
\hline & & & 24.88 & 24.88 & 0.00 & 5.04 & 5.07 & 0.03 \\
\hline & & & 24.86 & 24.88 & 0.02 & 5.08 & 5.09 & 0.01 \\
\hline
\end{tabular}


Table $10 \mathrm{D}$ and $\mathrm{T}$ values with international tolerance (IT) grade

\begin{tabular}{llllllll}
\hline Feature & \multicolumn{1}{l}{ X direction } & & & \multicolumn{2}{l}{ Y direction } \\
\cline { 2 - 3 } & D value & T value & IT grade & & D value & T value & IT grade \\
\hline A & 4.2426 & 68.2376 & IT11 & & 23.2379 & 45.8935 & IT9 \\
B & 13.4164 & 73.8896 & IT11 & & 13.4164 & 55.4172 & IT10 \\
C & 23.2379 & 45.8935 & IT9 & & 4.2426 & 109.1801 & IT12 \\
\hline
\end{tabular}

In all manufacturing processes, especially additive manufacturing, deviations from the nominal dimensions cannot be avoided due to number of reasons. These deviations from the nominal should not exceed a specific limit, in order that the manufactured component is able to fit. International tolerance (IT) grade numbers, according to ISO $286-1: 2010$, define whether a manufactured part lies within the desired tolerance or not [37]. For sizes up to $3150 \mathrm{~mm}$ there are twenty IT values, IT01, IT0, IT1,...., IT18; the lower the IT grade is, the higher is the precision of a machining process [38]. In this section, the tolerance grade calculations for the parts that were printed with the optimized parameter levels is presented. The process tolerance $(T)$ was calculated as follows:

$$
T=\frac{n}{0.45 \sqrt[3]{D}+0.001 D}
$$

where $\mathrm{D}$ is the geometrical mean dimension in $\mathrm{mm}$ and is calculated by the function:

$D=\sqrt{D_{\min } D_{\max }}$

where $D_{\min }$ and $D_{\max }$ are the limits of the dimension range. The $n$ value is calculated as:

$n=1000\left(D_{\operatorname{msmax}}-D_{\text {msmin }}\right)$

where $D_{\operatorname{msmax}}$ is the highest measured dimensional value of all nine parts and $D_{m s m i n}$ is the lowest measured dimensional value of all nine parts (see Table 9).

All values of $n$ were calculated and the corresponding IT grades have been obtained for all the items printed with the optimal parameter levels. The results are shown in Table 10. It has been observed that IT grades for $X$ direction range between IT9 and IT11. In case of $Y$ direction, IT grades are between IT 9 and IT12. The IT grades of the components printed with the optimal printing parameter levels are consistent with the permissible range of tolerance grades as per ISO standard UNI EN 20286-I (1995).

\section{Conclusions}

In the present study, the effect of four process parameters namely number of shells, printing temperature, infill rate and printing pattern on the dimensional accuracy of
FFF build parts was studied. Two levels were specified for number of shells, while printing temperature, infill rate and printing pattern had three levels. Taguchi's $L_{9}$ design of experiment was used along with grey Taguchi approach in order to find the optimum factor levels (first phase). Important process parameters, such as deposition angle and layer thickness were hold constant, due to their predictable effect on dimensional accuracy according to previous studies. After the selection of the parameter levels which gave the best dimensional accuracy, in a second phase, nine parts were printed using only these optimum levels. The tolerance of these nine parts was analyzed using the international tolerance grade. Summarizing the present research, the following conclusions may be drawn:

1 Analysis of Means showed that the levels which minimize dimensional deviation are: (a) Number of cells: 3 , (b) Printing temperature: $230^{\circ} \mathrm{C}$, (c) Infill rate: $10 \%$, (d) Printing pattern: $\mathrm{E}$.

2 The Analysis of Variance indicated that the factor which affects most dimensional accuracy is temperature, followed by number of cells, printing pattern and infill rate.

3 The new nine parts printed using the optimal printing parameter levels (second phase of experiments) possess better dimensional accuracy compared to the parts printed using Taguchi's $L_{9}$ design of experiment (first phase). This is evident from the values tabulated in Tables 3 and 9; dimensional deviation reaches the value of $0.1 \mathrm{~mm}$ in the case of Taguchi's $\mathrm{L}_{9} \mathrm{DOE}$, whereas in the case of the optimal printing parameter levels, the deviation values range between $0.00 \mathrm{~mm}$ and $0.03 \mathrm{~mm}$.

4 In the case of international grade study, it was revealed that the nine parts printed with the optimum process parameter levels possess IT grades between IT9 and IT12. This finding implies that these parts are consistent with the permissible range of standard tolerance grade as per ISO standard UNI EN 20286-I (1995).

As future perspectives, the optimization of surface roughness of the $L_{9}$ DOE parts and the optimization of both dimensional accuracy and surface roughness for the same parts may be mentioned. Grey Taguchi approach can be used for both cases. 
Compliace with ethical standards

Conflict of interest The authors declare that they have no conflict of interest.

\section{References}

1. Huang SH, Liu P, Mokasdar A, Hou L (2013) Additive manufacturing and its societal impact: a literature review. Int J Adv Manuf Technol 67:1191-1203. https://doi.org/10.1007/s0017 0-012-4558-5

2. Gurrala PK, Regalla SP (2014) Multi-objective optimisation of strength and volumetric shrinkage of FDM parts: a multi-objective optimization scheme is used to optimize the strength and volumetric shrinkage of FDM parts considering different process parameters. Virtual Phys Prototyp 9:127-138. https://doi. org/10.1080/17452759.2014.898851

3. Jiang J, Lou J, Hu G (2019) Effect of support on printed properties in fused deposition modelling processes. Virtual Phys Prototyp 14:308-315. https://doi.org/10.1080/17452759.2019.15688 35

4. Zhang X, Chen L, Mulholland T, Osswald TA (2019) Characterization of mechanical properties and fracture mode of PLA and copper/PLA composite part manufactured by fused deposition modeling. SN Appl Sci 1:616. https://doi.org/10.1007/s4245 2-019-0639-5

5. Vidakis N, Vairis A, Petousis M, Savvakis K, Kechagias J (2016) Fused deposition modelling parts tensile strength characterisation. Acad J Manuf Eng 14:87-94

6. Levy GN, Schindel R, Kruth JP (2003) Rapid manufacturing and rapid tooling with layer manufacturing (LM) technologies, state of the art and future perspectives. CIRP Ann Manuf Technol 52:589-609. https://doi.org/10.1016/S0007-8506(07)60206-6

7. Mohan N, Senthil P, Vinodh S, Jayanth N (2017) A review on composite materials and process parameters optimisation for the fused deposition modelling process. Virtual Phys Prototyp 12:47-59. https://doi.org/10.1080/17452759.2016.1274490

8. Srivastava M, Rathee S (2018) Optimisation of FDM process parameters by Taguchi method for imparting customised properties to components. Virtual Phys Prototyp 13:203-210. https ://doi.org/10.1080/17452759.2018.1440722

9. Sudin MN, Shamsudin SA, Abdullah MA (2016) Effect of part features on dimensional accuracy of FDM model. ARPN J Eng Appl Sci 11:8067-8072

10. Minetola P, Galati M (2018) A challenge for enhancing the dimensional accuracy of a low-cost 3D printer by means of self-replicated parts. Addit Manuf 22:256-264. https://doi. org/10.1016/j.addma.2018.05.028

11. Boschetto A, Bottini $L$ (2016) Design for manufacturing of surfaces to improve accuracy in fused deposition modeling. Robot Comput Integr Manuf 37:103-114. https://doi.org/10.1016/j. rcim.2015.07.005

12. Mohamed OA, Masood SH, Bhowmik JL (2015) Optimization of fused deposition modeling process parameters: a review of current research and future prospects. Adv Manuf 3:42-53. https:// doi.org/10.1007/s40436-014-0097-7

13. Turner BN, Gold SA (2015) A review of melt extrusion additive manufacturing processes: II. Materials, dimensional accuracy, and surface roughness. Rapid Prototyp J 21:250-261. https:// doi.org/10.1108/RPJ-02-2013-0017

14. Dey A, Yodo N (2019) A systematic survey of FDM process parameter optimization and their influence on part characteristics. J Manuf Mater Process 3:64. https://doi. org/10.3390/jmmp3030064

15. Valerga AP, Batista M, Salguero J, Girot F (2018) Influence of PLA filament conditions on characteristics of FDM parts. Materials 11:1322. https://doi.org/10.3390/ma11081322

16. Moza Z, Kitsakis K, Kechagias J, Mastorakis N (2015) Optimizing dimensional accuracy of fused filament fabrication using Taguchi design. In: 14th international conference on instrumentation, measurements, circuits and systems

17. Alafaghani A, Qattawi A, Alrawi B, Guzman A (2017) Experimental optimization of fused deposition modelling processing parameters: a design-for-manufacturing approach. Procedia Manuf 10:791-803. https://doi.org/10.1016/j.promf g.2017.07.079

18. Alafaghani A, Qattawi A (2018) Investigating the effect of fused deposition modeling processing parameters using Taguchi design of experiment method. J Manuf Process 36:164-174. https://doi.org/10.1016/j.jmapro.2018.09.025

19. Mahmood S, Qureshi AJ, Talamona D (2018) Taguchi based process optimization for dimension and tolerance control for fused deposition modelling. Addit Manuf 21:183-190. https ://doi.org/10.1016/j.addma.2018.03.009

20. Vishwas M, Basavaraj CK, Vinyas M (2018) Experimental investigation using Taguchi method to optimize process parameters of fused deposition modeling for $A B S$ and nylon materials. Mater Today Proc 5:7106-7114. https://doi.org/10.1016/j. matpr.2017.11.375.21

21. Chaidas D, Kitsakis K, Kechagias J, Maropoulos S (2016) The impact of temperature changing on surface roughness of FFF process. In: IOP conference series: materials science and engineering 161:012033. https://doi.org/10.1088/1757$899 x / 161 / 1 / 012033$

22. Chai $X$, Chai H, Wang $X$ et al (2017) Fused deposition modeling (FDM) 3D printed tablets for intragastric floating delivery of domperidone. Sci Rep 7:2829. https://doi.org/10.1038/s4159 8-017-03097-x

23. Yao T, Deng Z, Zhang K, Li S (2019) A method to predict the ultimate tensile strength of 3D printing polylactic acid (PLA) materials with different printing orientations. Compos Part B Eng 163:393-402. https://doi.org/10.1016/j.composites b.2019.01.025

24. Ricotti R, Ciardo D, Pansini F et al (2017) Dosimetric characterization of 3D printed bolus at different infill percentage for external photon beam radiotherapy. Phys Med 39:25-32. https ://doi.org/10.1016/j.ejmp.2017.06.004

25. Lubombo C, Huneault MA (2018) Effect of infill patterns on the mechanical performance of lightweight 3D-printed cellular PLA parts. Mater Today Commun 17:214-228. https://doi. org/10.1016/j.mtcomm.2018.09.017

26. Kechagias J, Aslani KE, Fountas NA, Vaxevanidis NM, Manolakos DE (2020) A comparative investigation of Taguchi and full factorial design for machinability prediction in turning of a titanium alloy. Measurement 151:107213. https://doi. org/10.1016/j.measurement.2019.107213

27. Zhou X, Hsieh SJ, Ting CC (2018) Modelling and estimation of tensile behaviour of polylactic acid parts manufactured by fused deposition modelling using finite element analysis and knowledge-based library. Virtual Phys Prototyp 13:177-190. https://doi.org/10.1080/17452759.2018.1442681

28. Padhi SK, Sahu RK, Mahapatra SS et al (2017) Optimization of fused deposition modeling process parameters using a fuzzy inference system coupled with Taguchi philosophy. Adv Manuf 5:231-242. https://doi.org/10.1007/s40436-017-0187-4

29. Cruz Sanchez FA, Boudaoud H, Muller L, Camargo M (2014) Towards a standard experimental protocol for open source 
additive manufacturing. Virtual Phys Prototyp 9:151-167. https ://doi.org/10.1080/17452759.2014.919553

30. Singh J, Singh R, Singh H (2017) Dimensional accuracy and surface finish of biomedical implant fabricated as rapid investment casting for small to medium quantity production. J Manuf Process 25:201-211. https://doi.org/10.1016/j.jmapro.2016.11.012

31. Sundaramoorthy R, Ravindran R (2019) Tool wear optimization in CNC milling operation of $\mathrm{Al}-\mathrm{Mg}_{2} \mathrm{Si}$ alloys by Taguchi method. SN Appl Sci 1:1093. https://doi.org/10.1007/s42452-019-1100-5

32. Satyanarayana G, Narayana KL, Nageswara Rao B (2019) Optimal laser welding process parameters and expected weld bead profile for P92 steel. SN Appl Sci 1:1291. https://doi.org/10.1007/ s42452-019-1333-3

33. Chen KT, Kao JY, Hsu CY, Da Hong P (2019) Multi-response optimization of mechanical properties for ZrWN films grown using grey Taguchi approach. Ceram Int 45:327-333. https://doi. org/10.1016/j.ceramint.2018.09.170

34. Singh R, Rashmi Bhingole P, Avikal S (2018) Gray based Taguchi optimization for heat treated welded joint. Mater Today Proc 5:19156-19165. https://doi.org/10.1016/j.matpr.2018.06.270

35. Sood AK, Ohdar RK, Mahapatra SS (2009) Improving dimensional accuracy of fused deposition modelling processed part using grey Taguchi method. Mater Des 30:4243-4252. https://doi. org/10.1016/j.matdes.2009.04.030

36. Aslani KE, Vakouftsi F, Kechagias JD, Mastorakis NE (2020) Surface roughness optimization of poly-jet 3D printing using Grey Taguchi method. In: 2019 international conference on control, artificial intelligence, robotics \& optimization (ICCAIRO), pp 213-218. https://doi.org/10.1109/ICCAIRO47923.2019.00041

37. Singh $R$, Garg $H$, Singh S (2018) Process capability comparison of fused deposition modelling for ABS and Fe-nylon (6) feedstock filaments. Mater Today Proc 5:4258-4268. https://doi. org/10.1016/j.matpr.2017.11.690

38. Kitsakis K, Kechagias J, Vaxevanidis N, Giagkopoulos D (2016) Tolerance assessment of polyjet direct 3D printing process employing the IT grade approach. Acad J Manuf Eng 14:62-69

Publisher's Note Springer Nature remains neutral with regard to jurisdictional claims in published maps and institutional affiliations. 